\title{
Expression of Fibroblast Growth Factor-2 and Fibroblast Growth Factor Receptor-1 in Thyroid Diseases: Difference between Neoplasms and Hyperplastic Lesions
}

\author{
KIYOSHI SHINGU, MINORU FUJIMORI, KEN-ICHI ITO, YOSHIHISA HAMA, YOSHIO KASUGA, \\ SHINYA KOBAYASHI, NOBUO ITOH*, AND JUN AMANO \\ Department of Surgery, *Department of Pathology, Shinshu University School of Medicine, Matsumoto 390-8621, Japan
}

\begin{abstract}
We studied the expression of both fibroblast growth factor-2 (FGF-2) and FGF receptor-1 (FGFR-1) in various histological types of human thyroid neoplastic and hyperplastic tissues to clarify the biological behavior of FGF-2. A total of 37 malignant tumors (24 papillary carcinomas, 10 follicular carcinomas, 3 anaplastic carcinomas), 8 follicular adenomas, and 12 adenomatous goiters were examined by immunohistochemical methods. With immunohistochemical staining, both FGF-2 and FGFR-1 were frequently detected in human thyroid carcinoma (79.2 to $100 \%$ and 80 to $100 \%$, respectively). In thyroid hyperplastic lesions such as adenomatous goiter, the FGF-2 immunoreactivity in follicular cells was detected in 2 of 12 adenomatous goiters (16.7\%). In contrast, FGFR-1 immunoreactivity was detected in $66.7 \%$ of cases of this disease. The endothelial cells of microvessels in the stroma adjacent to the neoplasms and hyperplastic lesions also showed cytoplasmic FGF-2 immunoreactivity. The difference between FGF-2 and FGFR-1 expression in adenomatous goiters was statistically significant $(P<0.05)$. Furthermore, the difference in FGF-2 immunoreactivity between carcinoma and adenomatous goiter was statistically significant $(P=0.0001)$. The present investigation demonstrated the possibility of an autocrine mechanism of action of FGF-2 in human thyroid carcinoma. Moreover, in thyroid hyperplastic lesions, FGF-2 derived from the stroma might be involved in the formation of nodular and/or diffuse goiters.
\end{abstract}

Key words: Fibroblast growth factor-2 (FGF-2), FGF receptor-1 (FGFR-1), Thyroid disease

(Endocrine Journal 45: 35-43, 1998)

THE fibroblast growth factor (FGF) family consists of polypeptide growth factors characterized by amino acid sequence homology, heparin-binding activity, the ability to promote angiogenesis, and mitogenic activity toward cells of epithelial, mesenchymal, and neural origin. At present, nine members of this growth factor family are known. Several FGFs were isolated as oncogenes from various tumors, and overexpression of different

Received: May 14, 1997

Accepted: November 6, 1997

Correspondence to: Dr. Kiyoshi SHINGU, Department of Surgery, Shinshu University School of Medicine, 3-1-1 Asahi, Matsumoto 390-8621, Japan members of the FGF family can lead to cell transformation [1, 2]. FGF-1 (acidic FGF) and FGF2 (basic FGF) are the first and best characterized members of this family. These prototypic FGFs are widely distributed in adult tissues [1,3]. We [4] previously demonstrated a close correlation between the expression of FGF-2 and the degree of malignancy in human thyroid neoplasms by immunohistochemical and biochemical procedures, and suggested that FGF-2 plays an important role in promoting lymph node metastasis.

In general, polypeptide growth factors mediate their mitogenic responses by binding to and activating specific cell-surface receptors. A large family of growth factor receptors possess 
cytoplasmic domains with intrinsic protein tyrosine kinase activities [5-7]. The FGF receptor (FGFR) family, which includes at least four species, also belongs to the tyrosine kinase receptor gene family [8].

To clarify the biological behavior of FGF-2 in human thyroid diseases, we investigated the expression of both FGF-2 and FGFR-1 (FLG), one of the high-affinity FGFRs for FGF-2, in various histological types of human thyroid neoplastic and hyperplastic tissues by immunohistochemical procedures.

\section{Materials and Methods}

\section{Tissue preparation}

Surgically removed thyroid tissues were utilized in this study. We examined 37 malignant tumors (24 papillary carcinomas, 10 follicular carcinomas, 3 anaplastic carcinomas), 8 follicular adenomas, and 12 adenomatous goiters. Histopathological diagnosis of the tumors was made according to the World Health Organization criteria [9]. Normal tissues, histologically confirmed, obtained from the noncancerous portion of papillary carcinomas in five patients were also used as controls. None of the patients received any medical treatment prior to our surgical intervention.

Small pieces of the removed tissues were immediately fixed in $10 \%$ phosphate-buffered formalin solution, dehydrated through a graded ethanol series, cleared in xylene, and embedded in paraffin. $4 \mu \mathrm{m}$ thick sections were cut on a sliding microtome and collected on glass slides coated with ovalbumin.

\section{Immunohistochemical staining methods}

After deparaffinization with xylene and passage through a graded ethanol series, one section was stained in hematoxylin and eosin, and the others were used for immunostaining. Immunoperoxidase staining was performed according to the avidinbiotin-peroxidase complex technique [10]. Endogenous peroxidase activity was inactivated by incubation with $0.3 \% \mathrm{H}_{2} \mathrm{O}_{2}$ in $100 \%$ methanol for $30 \mathrm{~min}$. Tissue sections were washed three times in $0.02 \mathrm{M}$ phosphate-buffered saline (PBS; $\mathrm{pH} 7.4$ ) for $5 \mathrm{~min}$ each and then incubated with blocking serum [ $5 \%$ normal goat serum in $0.02 \mathrm{M}$ PBS ( $\mathrm{pH}$ 7.4)] for $30 \mathrm{~min}$. All incubations were performed at room temperature in moist chambers. The sections were then reacted in the following solutions for $1 \mathrm{~h}$ each: (1) A solution of an antihuman basic FGF monoclonal antibody (WAKO Pure Chemical Industries, Osaka, Japan) diluted 1:100 and an anti-human FGFR (FLG) monoclonal antibody (Upstate Biotechnology Incorporated, Lake Placid, NY, USA) diluted 1: 200; (2) Biotinylated anti-mouse IgG solution and avidinbiotinylated peroxidase complex solution from a Vectastain ABC Kit (Vector Laboratories, Burlingame, CA, USA). All the antibody solutions were diluted with $0.02 \mathrm{M}$ PBS ( $\mathrm{pH}$ 7.4). After incubation in the antibody solutions, the sections were soaked in medium containing $0.05 \% 3,3^{\prime}-$ diaminobenzidine tetrahydrochloride and $0.01 \%$ $\mathrm{H}_{2} \mathrm{O}_{2}$ in $0.05 \mathrm{M}$ Tris buffer ( $\mathrm{pH} \mathrm{7.2)} \mathrm{for} 10 \mathrm{~min}$. The reaction was stopped by rinsing the slides with distilled water. The sections were then counterstained with hematoxylin, dehydrated, cleared in xylene, mounted under glass coverslips and examined and photographed under an Olympus Vanox AHB-LB light microscope (Olympus Optical, Tokyo, Japan).

The specificities of immunostaining were checked by omitting the single steps in the immunohistochemical protocol and replacing the primary antibody with non-immune serum or by incubation with the primary antibody preabsorbed with an excess of antigen [recombinant human basic FGF (Sigma, St. Louis, MO, USA), human FGF receptor preparation (Upstate Biotechnology Incorporated, Lake Placid, NY, USA)].

For statistical analyses, Fisher's exact test was employed. Differences were considered to be statistically significant when the $P$ value was $<0.05$.

\section{Western blotting analysis}

Papillary carcinomas and adenomatous goiters showing positive immunohistochemical staining for FGF-2 were further examined by Western blotting analysis to confirm the specificity of the staining according to the method described in our previous report [4]. Briefly, samples of these tissues had been frozen immediately after removal and stored at $-80^{\circ} \mathrm{C}$ until used. Tissue extracts were prepared 
by homogenization in $0.01 \mathrm{M}$ Tris- $\mathrm{HCl}$ ( $\mathrm{pH} 7.4)$, $1 \mathrm{M} \mathrm{NaCl}, 0.1 \% \mathrm{w} / \mathrm{v}$ 3-[(3-cholamidopropyl) dimethylammonio]-1-propanesulfonate (CHAPS), leupeptin $0.2 \mathrm{mg} / \mathrm{ml}$, and $0.001 \mathrm{M}$ phenylmethylsulfonylfluoride on ice. The homogenate was centrifuged and the supernatant was applied to a heparin-Sepharose column (Pharmacia, Piscataway, NJ, USA). FGF-2 was eluted with $2 \mathrm{M} \mathrm{NaCl}$ in $0.01 \mathrm{M}$ Tris $-\mathrm{HCl}\left(\mathrm{pH} \mathrm{7.4)}\right.$ at $20{ }^{\circ} \mathrm{C}$ and $0.1 \% \mathrm{w} / \mathrm{v}$ CHAPS. This solution was dissolved in sodium dodecyl sulfate (SDS) sample buffer and electrophoresed on an SDS-polyacrylamide gel. Recombinant human basic FGF was electrophoresed simultaneously. Samples were blotted from gels onto nitrocellulose membranes by electrotransfer. Blots were then incubated at $20^{\circ} \mathrm{C}$ for $30 \mathrm{~min}$ in buffer containing the same primary antibody used for immunohistochemical staining. Immunoreactive proteins were visualized by successive incubations with goat anti-mouse immunoglobulin conjugated with horseradish peroxidase (WAKO Pure Chemical Industries, Osaka, Japan) and 3,3'-diaminobenzidine tetrahydrochloride $/ \mathrm{H}_{2} \mathrm{O}_{2}$. The method for detection of FGFR-1 expression in papillary carcinomas employing Western blotting analysis was much the same as that described above except without using a heparin-Sepharose column.

\section{Results}

\section{FGF-2 and FGFR-1 expression in thyroid diseases}

The results of FGF-2 and FGFR-1 immunostaining of tissue sections obtained from patients with various thyroid diseases are summarized in Table
1. FGF-2 immunoreaction products were observed in the cytoplasm of tumor cells in 19 of 24 cases of papillary carcinoma (79.2\%) (Fig. 1), and those of FGFR-1 were observed in the cytoplasm in 22 of the 24 cases $(91.7 \%$ ) (Fig. 2). Tumor cells were positively stained for both FGF-2 and FGFR-1 in 8 of the 10 cases of follicular carcinoma $(80.0 \%)$. The reaction products of FGF-2 were mainly observed in the cytoplasm and some in the nucleus (Fig. 3), while those of FGFR-1 were mainly seen in the cytoplasm (Fig. 4). In all 3 cases of anaplastic carcinoma, immunohistochemical assays revealed positive staining for FGF-2 and FGFR-1 in the tumor cells. FGF-2-positive cells were stained more intensely than those in papillary and follicular carcinoma (Fig. 5). FGFR-1 staining was also found in the cytoplasm (Fig. 6).

With follicular adenomas, both FGF-2-positive cases $(62.5 \%)$ and FGFR-1- positive cases $(50.0 \%)$ showed similar staining to those of welldifferentiated follicular carcinoma. Immunoreaction products of FGF-2 were observed in the cytoplasm of the follicular cells in 2 of the 12 cases of adenomatous goiter (16.7\%) (Fig. 7). FGFR-1positive cells were found in 8 of the 12 cases $(66.7 \%)$ (Fig. 8).

The endothelial cells of microvessels in the stroma adjacent to the neoplasms and hyperplastic lesions also showed cytoplasmic FGF-2 immunoreactivity (Fig. 9). On the other hand, the endothelial cells away from the lesions did not show any cytoplasmic FGF-2 immunoreactivity. All of the 5 normal thyroid tissues were negative in these immunohistochemical assays. Controls using nonimmune serum instead of the primary antibody and the primary antibody preincubated with excess antigen showed no staining.

Table 1. Results of FGF-2 and FGFR-1 immunostaining in thyroid diseases

\begin{tabular}{lccccc}
\hline \multirow{2}{*}{ Thyroid disease } & Total no. of cases & $\begin{array}{c}\text { Positive FGF-2 } \\
\text { immunostaining }\end{array}$ & $\begin{array}{c}\text { Positive FGFR-1 } \\
\text { immunostaining }\end{array}$ \\
\cline { 3 - 7 } & & No. & $(\%)$ & No. & $(\%)$ \\
\hline Normal thyroid tissues & 5 & 0 & $(0)$ & 0 & $(0)$ \\
Papillary carcinoma & 24 & 19 & $(79.2)$ & 22 & $(91.7)$ \\
Follicular carcinoma & 10 & 8 & $(80.0)$ & 8 & $(80.0)$ \\
Anaplastic carcinoma & 3 & 3 & $(100)$ & 3 & $(100)$ \\
Follicular adenoma & 8 & 5 & $(62.5)$ & 4 & $(50.0)$ \\
Adenomatous goiter & 12 & 2 & $(16.7)$ & 8 & $(66.7)$ \\
\hline
\end{tabular}




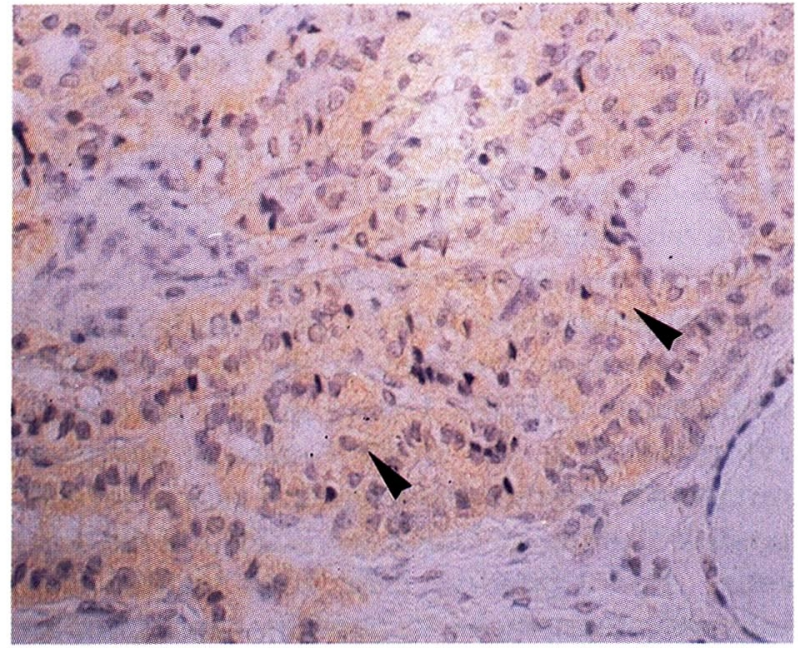

Fig. 1

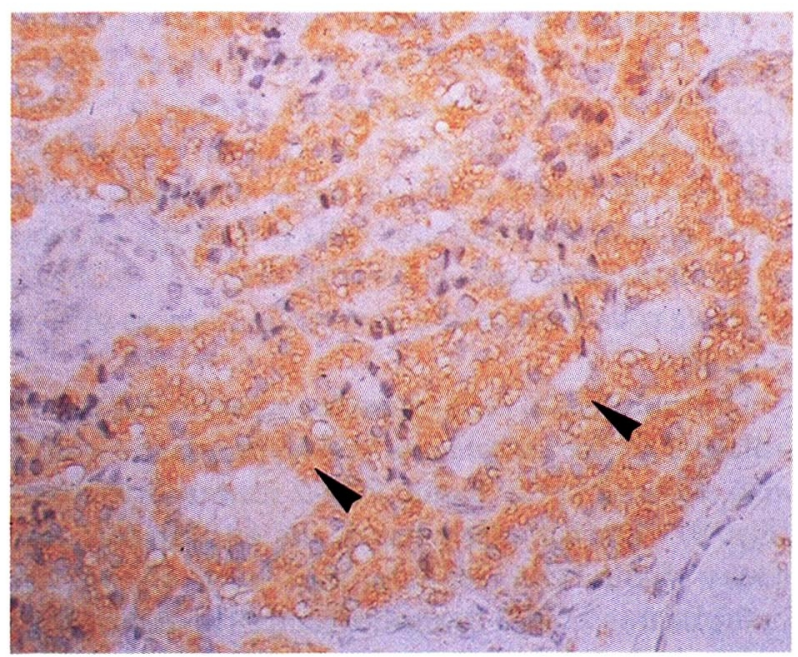

Fig. 2

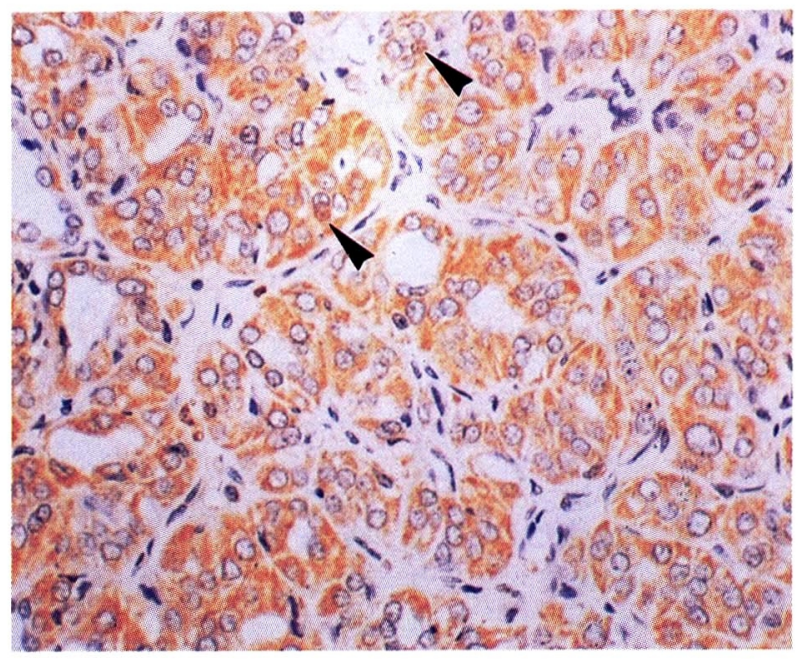

Fig. 3

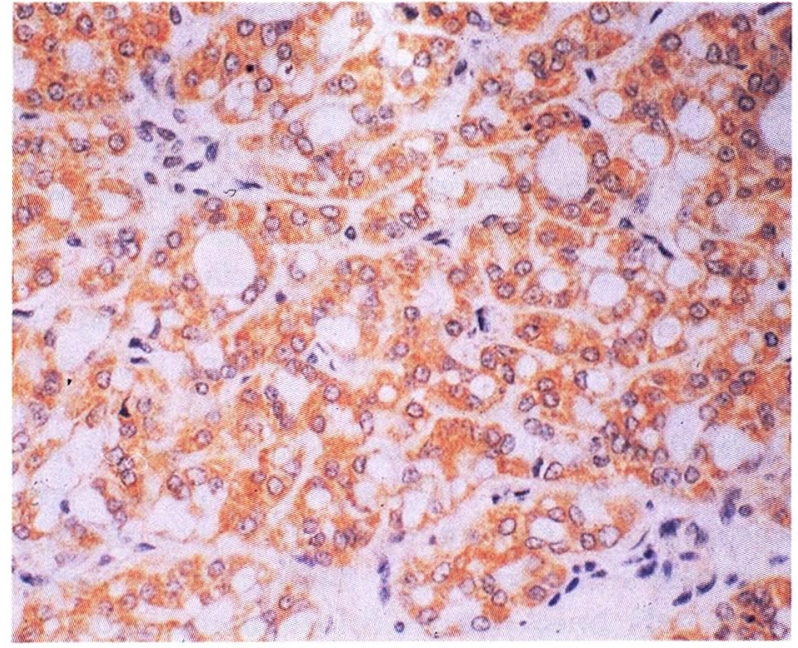

Fig. 4

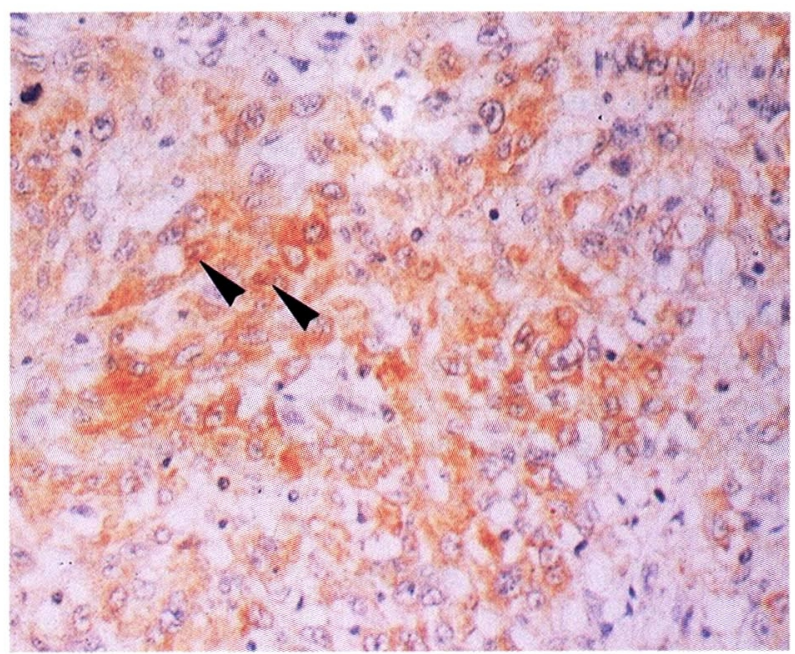

Fig. 5

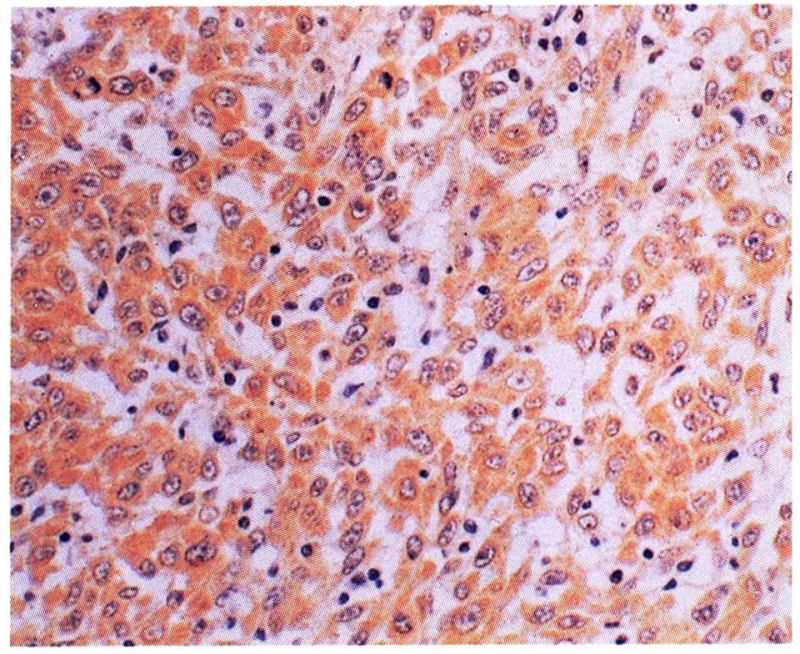

Fig. 6 


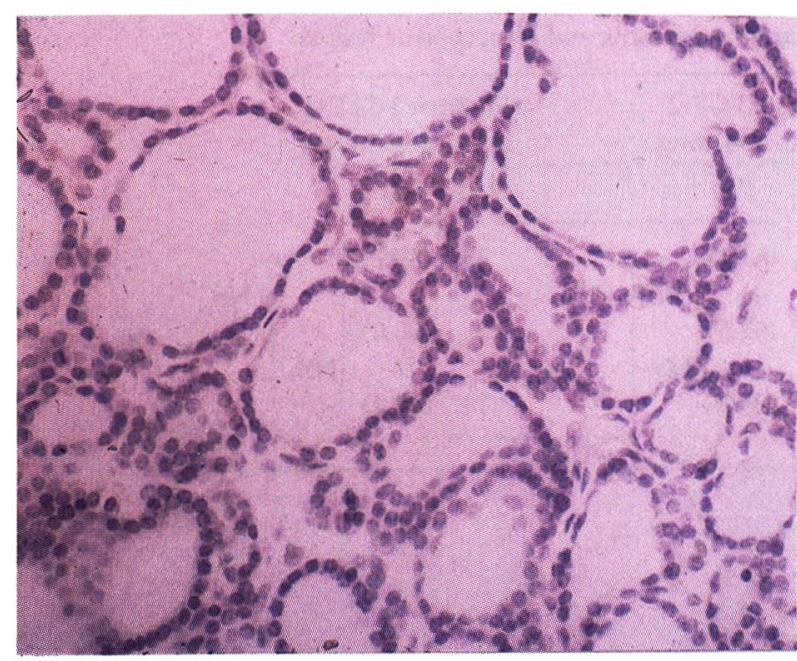

Fig. 7

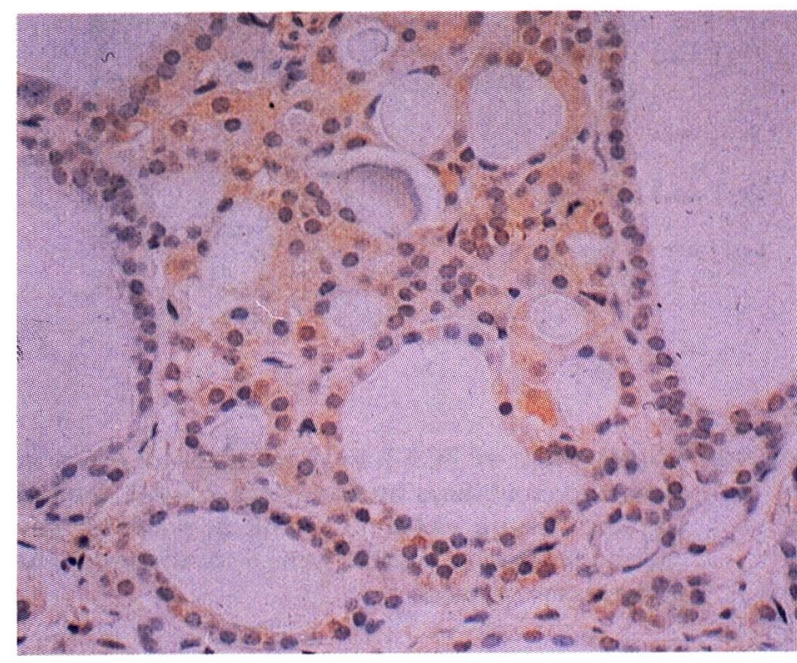

Fig. 8

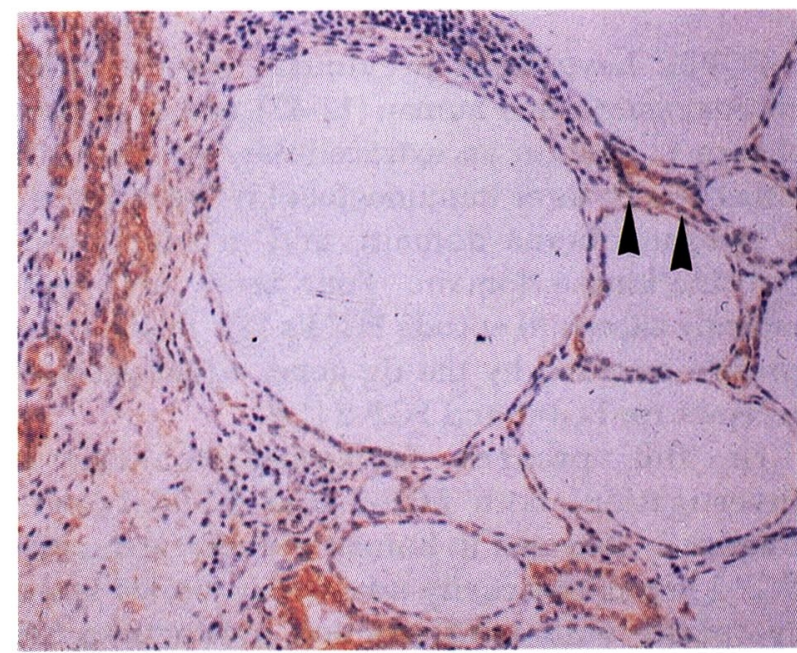

Fig. 9
Fig. 1. Light microscopic photograph showing the immunohistochemical localization of FGF-2 in papillary carcinoma. Reaction products were observed in the cytoplasm of the tumor cells (arrows) $(\times 400)$.

Fig. 2. Light microscopic photograph showing the immunohistochemical localization of FGFR-1 in papillary carcinoma. Reaction products were observed in the cytoplasm (arrows) $(\times 400)$.

Fig. 3. Light microscopic photograph showing the immunohistochemical localization of FGF-2 in follicular carcinoma. Reaction products were mainly observed in the cytoplasm and some were seen in the nucleus (arrows) $(\times 400)$.

Fig. 4. Light microscopic photograph showing the immunohistochemical localization of FGFR-1 in follicular carcinoma. Reaction products were mainly observed in the cytoplasm $(\times 400)$.

Fig. 5. Light microscopic photograph showing the immunohistochemical localization of FGF-2 in anaplastic carcinoma. Reaction products were mainly observed in the cytoplasm and some were seen in the nucleus (arrows) $(\times 400)$.

Fig. 6. Light microscopic photograph showing the immunohistochemical localization of FGFR-1 in anaplastic carcinoma. Reaction products are observed in the cytoplasm $(\times 400)$.

Fig. 7. Light microscopic photograph showing the immunohistochemical localization of FGF-2 in adenomatous goiter. No immunoreactivity was evident in the cytoplasm of the follicular cells $(x$ 400).

Fig. 8. Light microscopic photograph showing the immunohistochemical localization of FGFR-1 in adenomatous goiter. Reaction products were observed in the cytoplasm $(\times 400)$.

Fig. 9. Light microscopic photograph showing the immunohistochemical localization of FGF-2 in normal thyroid tissue adjacent to papillary carcinoma. Both the endothelial cells of microvessels in the stroma (arrows) and the papillary carcinoma cells invading the stroma showed positive staining for FGF-2 in the cytoplasm $(\times 200)$.

\section{Comparison of FGF-2 and FGFR-1 expression in neoplasms and hyperplastic lesions}

According to the histopathological diagnosis, thyroid diseases were divided into three groups: carcinoma, adenoma, and adenomatous goiter. FGF-2 and FGFR-1 expression in these three groups was compared. As shown in Table 2, the positive rates of FGF-2 and FGFR-1 in carcinoma were more than $80 \%$. Those in adenoma were more than $50 \%$. In contrast, in adenomatous goiter, although the FGF-2-positive rate was $16.7 \%$, that of FGFR-1 was $66.7 \%$. 
Table 2. Comparison of FGF-2 and FGFR-1 expression in neoplasms and hyperplastic lesions

\begin{tabular}{|c|c|c|c|c|c|c|c|c|c|}
\hline \multirow[t]{2}{*}{ Thyroid disease } & \multirow[t]{2}{*}{ Total no. of cases } & \multicolumn{4}{|c|}{$\begin{array}{c}\text { Positive FGF-2 } \\
\text { immunostaining }\end{array}$} & \multicolumn{4}{|c|}{$\begin{array}{l}\text { Positive FGFR-1 } \\
\text { immunostaining }\end{array}$} \\
\hline & & No. & $(\%)$ & & & No. & $(\%)$ & & \\
\hline Carcinoma & 37 & 30 & $(81.1)_{7}$ & 7 & ** & 33 & $(89.2)$ & & \\
\hline Adenoma & 8 & 5 & $(62.5)$ & NS & & 4 & (50.0) & NS & \\
\hline Adenomatous goiter & 12 & 2 & $(16.7)$ & ] & * & 14 & (66.7) & & \\
\hline
\end{tabular}

${ }^{*} P<0.05,{ }^{* *} P=0.0001 . \mathrm{NS}$, not significant.

In neoplasms (carcinoma and adenoma), there were no significant differences between FGF-2 and FGFR-1 expression, but the difference between FGF2 and FGFR-1 expression in adenomatous goiter was statistically significant $(P<0.05)$. Furthermore, the difference between carcinoma and adenomatous goiter in FGF-2 immunoreactivity was statistically significant $(P=0.0001)$. The differences between carcinoma and adenomatous goiter and between adenoma and adenomatous goiter in FGFR-1 expression were not significant.

\section{FGF-2 and FGFR-1 expression demonstrated by Western blotting analysis}

By Western blotting analysis, FGF-2 immunoreactivity was specifically detected at a molecular weight of $18 \mathrm{kDa}$ (Fig. 10). Recombinant human FGF-2 was reacted with monoclonal antiFGF-2 antibody in the region of the $18 \mathrm{kDa}$ form (Fig. 10, lane 1). In all of the papillary carcinomas examined, immunoreactive FGF-2 was also observed as an $18 \mathrm{kDa}$ band (Fig. 10, lanes 3 and 4). The $18 \mathrm{kDa}$ band was also observed in all cases of adenomatous goiter examined (Fig. 10, lanes 5 and 6). On the other hand, no immunoreactivity was seen in normal thyroid tissues (Fig. 10, lane 2). Furthermore, FGFR-1 expression was confirmed by Western blotting analysis (Fig. 11). In all of the papillary carcinomas, FGFR-1 immunoreactivity was observed as a band of approximately $95 \mathrm{kDa}$ (Fig. 11, lane 3) or bands of 95 and $120 \mathrm{kDa}$ (Fig. 11, lane 2). These bands corresponded to those of FGFR-1 [11]. Normal thyroid tissues showed no FGFR-1 immunoreactivity (Fig. 11, lane 1).

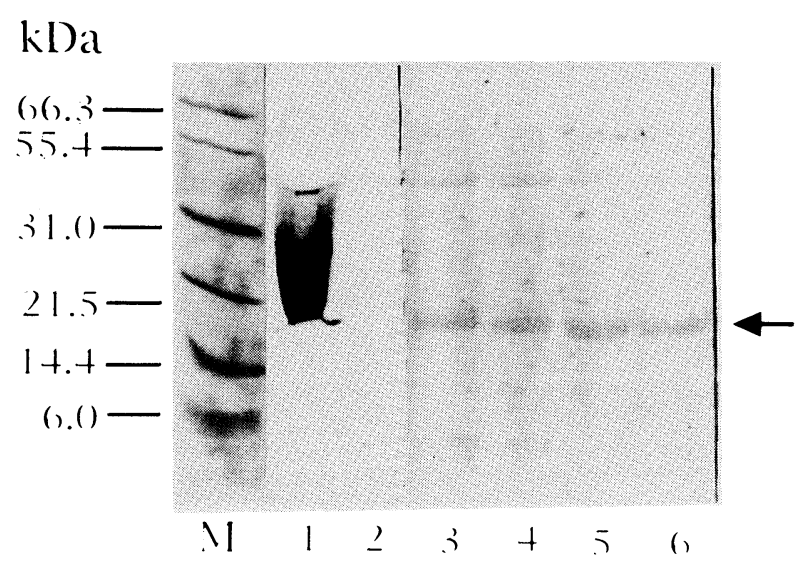

Fig. 10. Western blot of FGF-2 in thyroid tissue extracts. Lane 1, recombinant human bFGF; Lane 2, normal thyroid tissue extracts; Lane 3,4 , papillary carcinoma tissue extracts; Lane 5, 6, adenomatous goiter tissue extracts.

\section{Discussion}

FGFRs have been previously identified in chicken, mouse and human [12-17], and have been shown to contain an extracellular domain with either two or three immunoglobulin-like domains, a transmembrane domain, and a cytoplasmic tyrosine kinase domain. Four genes have been recently shown to encode FGFRs [8]. FGFR-1 is a protein encoded by the flg gene, a high affinity receptor for FGF-1 and FGF-2 [18].

In the present immunohistochemical investigation, both FGF-2 and FGFR-1 were frequently detected in human thyroid carcinoma. FGF-2 immunoreactivity was mainly located in the cytoplasm with some reaction products in the nucleus. Four forms of FGF-2 with molecular 


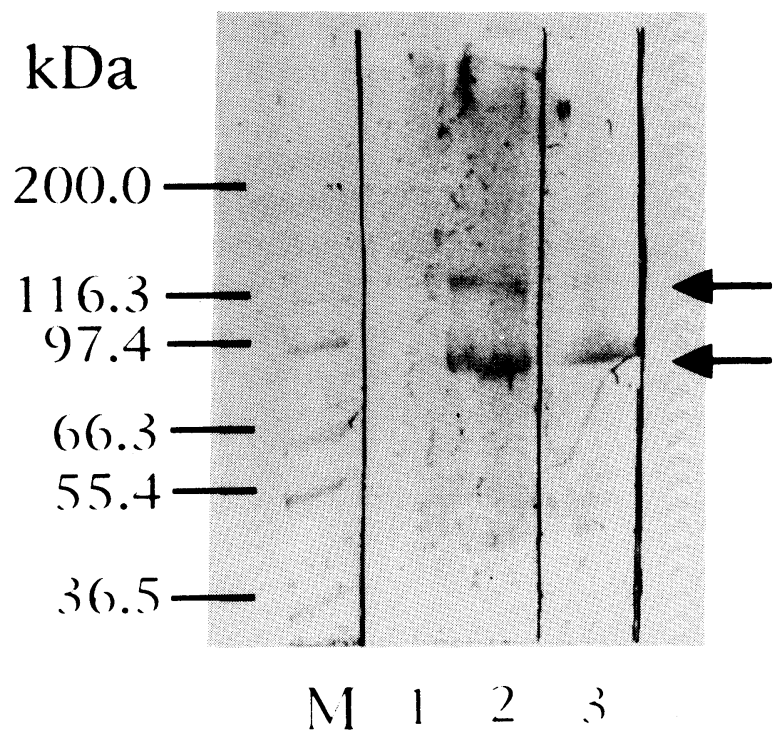

Fig. 11. Western blot of FGFR-1 in thyroid tissue extracts. Lane 1, normal thyroid tissue extracts; Lane 2, 3, papillary carcinoma tissue extracts.

weights of $18,22,22.5$ and $24 \mathrm{kDa}$ have been identified [19, 20]. All these forms of FGF-2 are derived from a single messenger RNA (mRNA). The high molecular weight species appear to be the $\mathrm{NH}_{2}$-terminal-extended form derived from a single FGF-2 mRNA via the use of three CUG initial codons instead of the usual AUG codons. In addition, the $\mathrm{NH}_{2}$-terminus in the high-molecularweight form of FGF-2 was shown to contain the nuclear localization signal [21, 22]. In our immunohistochemical study, FGF-2 immunoreactivity in the nucleus was observed in a minority of both follicular and anaplastic carcinoma cells and follicular adenoma cells. With papillary carcinomas, no immunostaining was seen in the nuclei of the tumor cells. Although FGF-2 localized in the nucleus may play an important role directly in tumor growth, it seems that FGF-2 in the nucleus is not always concerned with the aggressiveness of the tumor. The FGFR-1 immunostaining pattern was similar to that of FGF-2. FGFR-1 immunoreactivity was expected to be present on the cell surface, but it was mainly observed in the cytoplasm with some on the cell surface and in the nucleus. There are two possible explanations for these unexpected results. One is the expansion of FGFR-1 into the cytoplasm in the process of making thin sections, and the other is FGFR-1 taken into the cytoplasm after combination with FGF-2. Moreover, Maher [23] demonstrated that there was a time- and dose-dependent increase in the association of FGFR-1 immunoreactivity with the nucleus when cells were treated with FGF-2.

Even if both growth factor and receptor are present in some tumors, the autocrine mechanism is not always acting on the tumor growth, because it is not evidence that the growth factor functions as the growth signal directly. Nevertheless, as both FGF-2 and FGFR-1 immunostaining showed high positive rates in thyroid carcinoma and FGF-2 expression was significantly increased as compared with that in adenomatous goiter $(P=0.0001)$, it is possible that the autocrine mechanism of action of FGF-2 plays an important role in the growth of this type of tumor. Moreover, as shown previously [24, 25], FGF-2 secreted from cytoplasm by some mechanisms may be involved in tumor growth by promoting tumor angiogenesis.

In thyroid hyperplastic lesions such as adenomatous goiter, FGF-2 immunoreactivity in follicular cells was detected in 2 of 12 cases (16.7\%). On the other hand, FGFR-1 immunoreactivity was detected in $66.7 \%$ of cases of this disease. The difference between FGF-2 and FGFR-1 expression in adenomatous goiters was statistically significant $(P<0.05)$, but in most adenomatous goiters, the endothelial cells of microvessels in the stroma adjacent to the nodular lesions also showed cytoplasmic FGF-2 immunoreactivity similarly to other neoplastic diseases. Therefore, in adenomatous goiters, FGF-2 derived from the stroma might be involved in the formation of nodular and/or diffuse goiters.

In the present study, no FGF-2 or FGFR-1 immunoreactivity was detected in normal thyroid tissue, but we cannot exclude the possibility that relatively small amounts of FGF-2 and FGFR-1 in normal thyroid tissue were undetectable by our methods. Kodama et al. [26] reported weak immunoreactivity or none at all in normal thyroid tissue (follicular cells and other tissue elements such as peripheral nerve, smooth muscle and fibroblast). Eggo et al. [27] reported that there was no specific staining for FGF-1 or FGF-2 in normal thyroid tissue.

Our immunoblotting FGF-2 and FGFR-1 studies supported the results of immunohistochemical examinations. Some FGFR-1 extracts from papillary carcinomas showed two molecular weight bands- 
95 and $120 \mathrm{kDa}$. Heterogenity of FGFR-1 due to alternative splicing of the mRNA was reported previously [14].

Recently, Fujimoto et al. [28] reported that serum FGF-2 could be useful in the diagnosis of patients with renal cell carcinoma and was a prime candidate as a tumor marker with a high specificity for this malignant disease. In patients with thyroid carcinoma, the serum FGF-2 level might be high because of the high detection rate of FGF-2 in tissue immunostaining. With the exception of medullary carcinoma, there are no effective tumor markers for malignant thyroid diseases, so that the serum FGF-2 level is worth measuring in patients with thyroid carcinoma.

The findings of the present immunohistochemical study suggested that FGF-2 plays an important role in promoting tumor growth and the formation of hyperplasia in the thyroid gland, but the cause of tumor growth or hyperplasia cannot be explained by the actions of this one growth factor alone. Further molecular oncological studies are necessary to clarify the actions of FGF-2 in tumor growth and hyperplasia.

\section{References}

1. Burgess WH, Maciag $\mathrm{T}$ (1989) The heparin-binding (fibroblast) growth factor family of proteins. Annu Rev Biochem 58: 575-606.

2. Yayon A, Klagsbrun M (1990) Autocrine transformation by chimeric signal peptide-basic fibroblast growth factor: Reversal by suramin. Proc Natl Acad Sci USA 87: 5346-5350.

3. Gospodarowicz D, Neufeld G, Schweigerer L (1987) Fibroblast growth factor: Structural and biological properties. J Cell Physiol Suppl 5: 15-26.

4. Shingu K, Sugenoya A, Itoh N, Kato R (1994) Expression of basic fibroblast growth factor in thyroid disorders. World J Surg 18: 500-505.

5. Yarden Y, Ullrich A (1988) Molecular analysis of signal transduction by growth factors. Biochemistry 27: 3113-3119.

6. Schlessinger J (1988) The epidermal growth factor as a multifunctional allosteric protein. Biochemistry 27: 3119-3123.

7. Hanks SK, Quinn AM, Hunter T (1988) The protein kinase family: Conserved features and deduced phylogeny of the catalytic domains. Science 241: 4552.

8. Johnson DE, Williams LT (1993) Structural and functional diversity in the FGF receptor multigene family. Adv Cancer Res 60: 1-41.

9. Hedinger C, Williams ED, Sobin LH (1988) Histological typing of thyroid tumours. In: International Histological Classification of Tumours, World Health Organization. 2nd ed, Berlin. Springer-Verlag, No. 11: 5-18.

10. Hsu S, Raine L, Fanger H (1981) The use of antiavidin antibody and avidin-biotin-peroxidase complex in immunoperoxidase technique. Am J Clin Pathol 75: 816-821.

11. Ruta M, Burgess W, Givol D, Epstein J, Kaplow J, Crumley G, Dionne C, Jaye M, Schlessinger J (1989) Receptor for acidic fibroblast growth factor is related to the tyrosine kinase encoded by the fms -like gene (FLG). Proc Natl Acad Sci USA 86: 8722-8726.

12. Lee PL, Johnson DE, Cousens LS, Fried VA, Williams LT (1989) Purification and complementary DNA cloning of a receptor for basic fibroblast growth factor. Science 245: 57-60.

13. Pasquale EB, Singer SJ (1989) Identification of a developmentally regulated protein-tyrosine kinase by using anti-phosphotyrosine antibodies to screen a cDNA expression library. Proc Natl Acad Sci USA 86: 5449-5453.

14. Johnson DE, Lee PL, Lu J, Williams LT (1990) Diverse forms of a receptor for acidic and basic fibroblast growth factors. Mol Cell Biol 10: 47284736.

15. Reid HH, Wilks AF, Bernard O (1989) Two forms of the basic fibroblast growth factor receptor-like mRNA are expressed in the developing mouse brain. Proc Natl Acad Sci USA 87: 1596-1600.

16. Safran A, Avivi A, Orr-Urtereger A, Neufeld G, Lonai P, Givol D, Yarden Y (1990) The murine flg gene encodes a receptor for fibroblast growth factor. Oncogene 5: 635-643.

17. Mansukhani A, Moscatelli D, Talarico D, Levytska V, Basilico C (1990) A murine fibroblast growth factor (FGF) receptor expressed in CHO cells is activated by basic FGF and Kaposi FGF. Proc Natl Acad Sci USA 87: 4378-4382.

18. Dionne CA, Crumley G, Bellot F, Kaplow JM, Searfoss G, Ruta M, Burgess WH, Jaye M, Schlessinger J (1990) Cloning and expression of two distinct high-affinity receptors cross-reacting with acidic and basic fibroblast growth factors. EMBO J 9: 2685-2692.

19. Florkiewicz RZ, Sommer A (1989) The human bFGF gene encodes four polypeptides: Three initiate translation from non-ATG codons. Proc Natl Acad Sci USA 86: 3978-3981. 
20. Prats $H$, Kaghad H, Prats AC, Klagsbrun M, Lelias JM, Liauzun P, Chalon P, Tauber JP, Amalric F, Smith JA, Caput D (1989) High molecular mass forms of basic fibroblast growth factor are initiated by alternative CUG codons. Proc Natl Acad Sci USA 86: 1836-1840.

21. Renko M, Quarto N, Morimoto T, Rifkin DB (1990) Nuclear and cytoplasmic localization of different basic fibroblast growth factor species. J Cell Physiol 144: 108-114.

22. Quarto N, Finger FP, Rifkin DB (1991) The $\mathrm{NH}_{2-}$ terminal extension of high molecular weight $b F G F$ is a nuclear targeting signal. J Cell Physiol 147: 311318.

23. Maher PA (1996) Nuclear translocation of fibroblast growth factor (FGF) receptors in response to FGF2. J Cell Biol 134: 529-536.

24. Zagzag D, Miller DC, Sato Y, Rifkin DB, Burstein DE (1990) Immunohistochemical localization of basic fibroblast growth factor in astrocytomas. Cancer Res 50: 7393-7398.
25. Kandel J, Bossy-Wetzel E, Radvanyi F, Klagsbrun M, Folkman J, Hanahan D (1991) Neovascularization is associated with a switch to the export of bFGF in the multistep development of fibrosarcoma. Cell 66: 1095-1104.

26. Kodama M, Daa T, Kashima K, Yokoyama S, Nakayama I, Noguchi S (1994) Immunohistochemical localization of acidic and basic fibroblast growth factor in human benign and malignant thyroid lesions. Jpn J Clin Oncol 24: 6673.

27. Eggo MC, Hopkins JM, Franklyn JA, Johnson GD, Sanders DSA, Sheppard MC (1995) Expression of fibroblast growth factors in thyroid cancer. J Clin Endocrinol Metab 80: 1006-1011.

28. Fujimoto $K$, Ichimori $Y$, Yamaguchi $H$, Arai $K$, Futami T, Ozono S, Hirao Y, Kakizoe T, Terada M, Okajima E (1995) Basic fibroblast growth factor as a candidate tumor marker for renal cell carcinoma. Jpn J Cancer Res 86: 182-186. 